\title{
Artigos Ensaios
}

\section{A PERCEPÇÃO SOBRE A CIÊNCIA NA VERTIGEM DO CINEMA: CONSIDERAÇÕES ACERCA DE UM CORPO OUE CAI}

\section{Márcio Barreto}

A canção "Pecado original" foi composta por Caetano Veloso, em 1978, para a trilha sonora de A dama do lotação, filme baseado na obra de Nelson Rodrigues e dirigido por Neville D'Almeida. Abaixo, podemos ler a primeira estrofe:

Todo dia, toda noite

Toda hora, toda madrugada

Momento e manhã

Todo mundo, todos os segundos do minuto

Vivem a eternidade da maçã

Tempo da serpente nossa irmã

Sonho de ter uma vida sã.

Essa canção popular traz em sua poesia a associação cultivada pelo senso comum entre a imagem da maçã e a queda do paraíso. Embora não haja nas Escrituras qualquer menção a esse fruto específico, a maçã impôs-se como símbolo do pecado original que condicionou o humano à temporalidade e ao seu inexorável retorno ao chão.

Jung [1] estabeleceu um caráter subdeterminado aos arquétipos que condensam várias situações numa única representação. A maçã representa também outro pilar da cultura ocidental: ainda que não haja na obra de Isaac Newton qualquer referência ao fruto [2], a queda de uma maçã teria revelado a Newton o enunciado da gravitação universal, lei cuja formulação matemática representa o coroamento da ciência moderna. Lenda reducionista do ponto vista da história da ciência que, no entanto, propaga-se no senso comum encarnada na imagem da maçã. Apesar da trivial associação entre as maçãs da gravitação universal e da queda do paraíso, é interessante o papel que o hábito pode desempenhar na cristalização de um símbolo público. Whitehead, ao referir-se à função social da linguagem afirmou que "uma palavra é um símbolo associado à sua própria história, aos seus diversos sentidos e ao seu papel gerativo na literatura ordinária" [3].

A queda aparece também como um componente importante para a ciência em outra lenda: Einstein, ao reformular a teoria gravitacional de Newton através da relatividade geral, teria retirado inspiração ao observar a queda de um pintor de paredes através da sua janela. 
De concreto nessa história, temos a declaração do próprio Einstein: "estava sentado numa cadeira na repartição de patentes em Berna quando de súbito me ocorreu um pensamento: se uma pessoa cai livremente, não sente o próprio peso. Fiquei abismado. Este simples pensamento provocou-me uma impressão profunda.

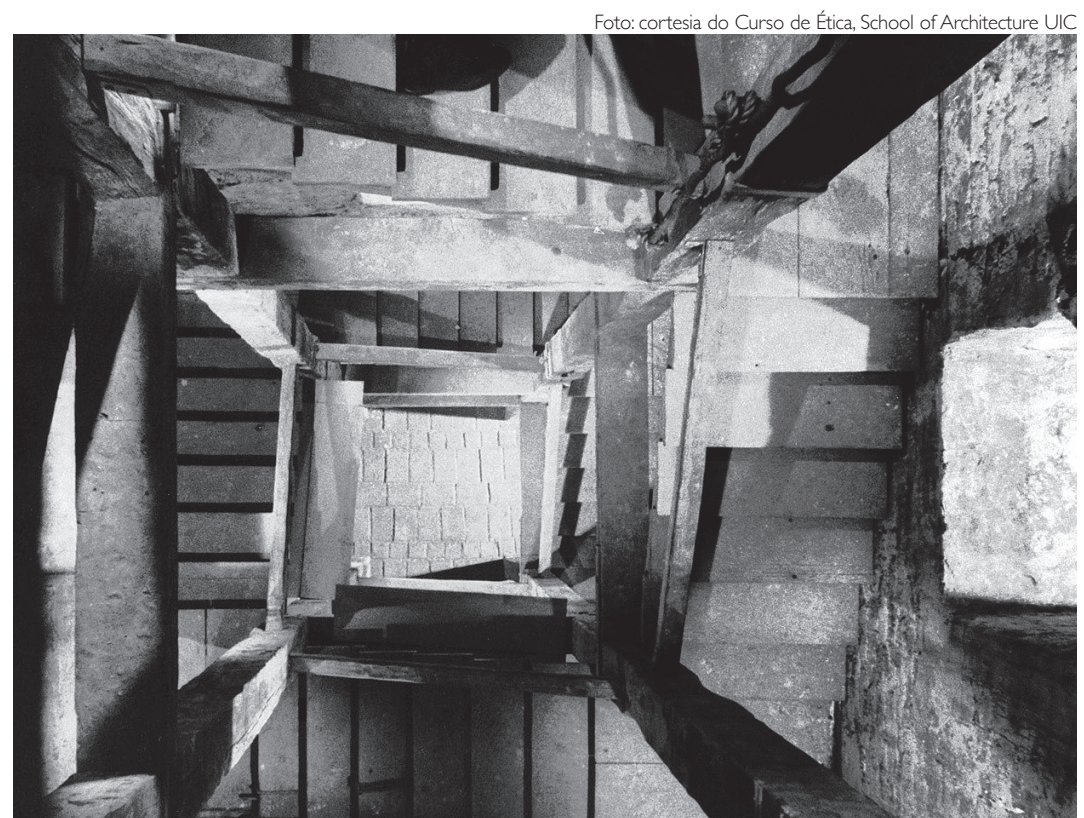

Figura 1. Cena de Um corpo que cai em que o dolly-zoom foi empregado
Carlotta Valdez, e irá tentar suicídio. O detetive hesita diante do argumento inverossímil do colega, mas aceita a proposta e passa a segui-la com um misto de cientificidade na análise do encadeamento das relações entre causas e efeitos e perplexidade diante da possibilidade não totalmente descartada da possessão que vitima a esposa de Elster. Impeliu-me para a teoria da gravitação" [4].

A verticalidade, inerente às quedas do paraíso, da maçã de Newton e da pessoa imaginada por Einstein, ao movimento ascensional ao qual assistimos no interior da obra de Platão e à concepção judaico-cristã de céu e inferno, é marcante na cultura ocidental.

No filme Um corpo que cai (Vertigo), de Alfred Hitchcock, o dolly-zoom, movimento simultâneo da câmera e da lente, criado para o filme pelo diretor de fotografia e pelo próprio operador de câmera, dá ao espectador o efeito de uma vertigem. Numa perspectiva topológica do filme, esse efeito técnico inovador e as três quedas de pessoas instauram a verticalidade como uma dimensão essencial da trama e com a qual o espectador não pode deixar de lidar.

A narrativa flui em São Francisco, nos Estados Unidos, onde o detetive John "Scottie" Ferguson, interpretado por James Stewart, sofre de acrofobia, sequela do trauma da perda de um colega de trabalho que caiu do alto de um edifício ao tentar salvar o protagonista de sua própria queda.

Um corpo que cai coloca fatos sobrenaturais e investigação racional em alternância na consciência do espectador: Scottie encontra um antigo colega de faculdade, Gavin Elster, o qual pede que siga sua esposa, Madeleine, pois acredita que ela está possuída por uma ancestral,
A paixão entre Scottie e a investigada, interpretada por Kim Novak, aflora quando ela se joga na baía de São Francisco e é salva por ele. Os dois então se enamoram e passam a se encontrar. Num desses encontros, ela subitamente sobe aflita ao alto da torre da igreja da missão San Juan Batista e o obriga a enfrentar a acrofobia para acompanhá-la, mas seu esforço é vão: o corpo dela caindo enquanto ele tentava subir o remeterá a um novo trauma causado por uma queda, cuja sequela será a de um quadro depressivo. Ele se recupera, mas fica obcecado por reencontrar a falecida Madeleine - luta inglória até que vê na rua alguém que com ela se parece: Judy (também interpretada por Kim Novak).

Judy, de fato, era quem ele buscava, mas ela nega. Ela fingiu ser a verdadeira esposa de Elster, a qual fora lançada pelo marido do alto da torre, enquanto a impostora desaparecia escada acima da vida de Scottie. O plano foi traçado por Elster, pois sabia que a acrofobia de Scottie o impediria de chegar ao topo da torre, mas não de testemunhar a queda da verdadeira Madeleine e, assim, mascarar o assassinato. No final, Scottie descobre o truque e volta à igreja para, sob forte emoção, reconstituir a cena do crime com Judy que, acuada entre a paixão que construíra por Scottie e sua cumplicidade no crime, cai do alto da torre ao se assustar com a presença de uma freira. 
A queda é, portanto, uma espécie de fio condutor no filme de Hitchcock. Como bem formulou Zizek, "a queda é uma iguaria filosófica em Um corpo que cai" [5]. Um desnível implica uma energia potencial em um corpo, um presente vertiginoso pela possível conversão daquela energia em energia cinética. Hitchcock modula essa virtualidade deslocando verticalmente o referencial através do movimento do olhar de Scottie, ora para baixo, com o pavor de sucumbir ao chamado do solo, ora para cima, com o desejo de libertação do descontrole de sua memória de quedas anteriores, pois o passado se atualiza perturbadoramente na mente do protagonista pelo pavor diante da altura.

A iguaria à qual Zizek se refere pode ser melhor saboreada se considerarmos que a queda, ao ser tomada como central no filme, faz ressoar no espectador a verticalidade que marca os fundamentos da cultura ocidental, de Platão a Einstein, da queda do paraíso à queda da maçã de Newton. Outros filmes privilegiam o eixo vertical, como Asas do desejo, de Wim Wenders, ou O anticristo, de Lars von Trier, mas Um corpo que cai é o que mais assume a queda como uma espécie de personagem, o que faz o filme excepcionalmente forte, a ponto de ele aparecer em quase todas as classificações dos melhores já produzidos.

Talvez à revelia do diretor, a vertigem parece conter outra vertigem, inata ou germinal em nossa cultura. Essa especulação mereceria uma investigação mais profunda, mas vale a pena explorarmos a capacidade de Um corpo que cai de deslocar a percepção do espectador para esse aspecto que transcende a narrativa do filme. Tomemos um exemplo de deslocamento da percepção que não vem do cinema: o haikai escrito pelo japonês Yosa Buson no século XVIII:

Com a luz do relâmpago

Barulho de pingos -

Orvalho no bambu.

Buson descreve sua súbita audição do som do orvalho, até então oculto. Provavelmente, não é a luz do relâmpago que o faz ver os pingos e, depois, ouvir o som do gotejamento, mas é o espanto que o relâmpago traz ao riscar o céu que dá ao poeta a audição do gotejamento que se manteria na penumbra de sua consciência. O relâmpago e o barulho do orvalho no bambu não estão interligados, mas a trinca de luz repentina no céu revela o barulho dos pingos porque a expectativa do trovão despertou a audição do poeta. O encontro dos seus olhos com a luz do relâmpago Ihe dá a percepção do que pouco ou nada se relacionava com a paisagem.

De acordo com Santos, "a ausência do som dilacerante do raio é a hipótese mais do que plausível [da audição do gotejamento] se considerarmos que a percepção auditiva de Buson é despertada para a queda do raio para imediatamente descobrir a queda do orvalho, isto é, passar da ausência de uma das expressões mais terríveis da natureza à presença de sua expressão mais suave" [6]. O recorte constantemente realizado pela mente na paisagemao seu redor oculta uma infinidade de percepções. Diante da tela de cinema, não é diferente, mas as múltiplas possibilidades de acesso à realidade desdobram-se em insuspeitáveis agenciamentos pela empatia entre a temporalidade do filme e o murmúrio ininterrupto da vida interior do espectador.

Artaud [7] afirmou que o cinema reverbera a realidade íntima do cérebro, mas trata-se de uma realidade que, ao invés de revelar o todo, apresenta-se na impossibilidade de alcançar essa totalidade que se insinua no encontro entre o filme e a quem a ele se expõe. Trata-se de uma fissura no pensamento que se abre em múltiplas vozes, em arranjos que subvertem hábitos cristalizados, associações óbvias, fetiches baratos e emoções vulgares. Mais do que fundir o espectador num universo onírico, o cinema tem a capacidade de promover reconfigurações que por vezes vão além do próprio repertório de experiências, de conhecimentos e de pensamentos do espectador.

As imagens no cinema são menos eficazes para fazer o espectador pensar do que para colocar o pensamento diante de sua incapacidade de pensar o todo. "A esse respeito, Jean-Louis Shefer [...] diz que a imagem cinematográfica [...] longe de tornar o pensamento visível, como queria Eiseinstein, se dirige, ao contrário, àquilo que não se deixa pensar no pensamento" [8]. É nesse sentido que o cinema pensa: menos naquilo que o cineasta pretende no argumento cinematográfico e mais naquilo que amplia o campo perceptivo do espectador. O cinema é capaz de um deslocamento da percepção cujo efeito é similar ao que experimentou 
Buson por causa do relâmpago. No entanto, se o poeta se dá conta daquilo que se camuflava em sua consciência, a expansão da percepção pelo cinema não necessariamente incorpora à consciência do espectador tudo o que é potencialmente perceptível, pois a sua própria percepção "é uma experiência incompleta, excede as potencialidades que aparecem num primeiro plano que não esgotam a realidade daquilo que é percebido" [9]. O dolly-zoom e os múltiplos desníveis em Um corpo que cai abrem ao espectador o acesso a um sistema de símbolos, como o da verticalidade ou da maçã, ainda que os agenciamentos decorrentes da expansão do campo não sejam racionalmente elaborados por ele. A hipótese carece de verificação empírica, mas não se trata aqui de provar que o filme produz um efeito determinado e sim de perscrutar seu potencial para exceder a percepção e o pensamento do espectador.

As possibilidades de transcendência virtualmente contidas em Um corpo que cai vão além da ressonância entre a vertigem dos desníveis gravíticos e o platonismo ou a religiosidade ocidental. Apesar da tensão entre o que está acima e o que está abaixo, a película é marcada também por eventos em que essa tensão se resolve em descargas que, como relâmpagos, unem céu e terra.

O primeiro e ainda incipiente indício de descarga ocorre quando Scottie e a impostora Madeleine se beijam no instante em que a onda do mar quebra no rochedo. Mas é no final do filme,

na hipnótica luz que banha o interior do quarto do hotel, quando Judy distraidamente coloca o colar de Carlotta, que Scottie tem o lampejo que resolve para ele o mistério da trama. A cena sutilmente sugere que ambos se arrumam para sair após seus corpos terem sido percorridos por uma torrente de prazer.
Scottie percebe que Madeleine e Judy, uma que foi para cima e outra que ficou embaixo, são definitivamente a mesma pessoa.

O curto-circuito entre o acima e o abaixo cura a acrofobia de Scottie, fazendo passar do estado de fraqueza ao de potência, do bem comportado detetive aposentado ao animal enfurecido, e acrescenta outra dimensão ao filme. Como um relâmpago que equaliza céu e terra, a torrente de elétrons entre Judy e Madeleine subverte a rigidez do eixo vertical que paralisava Scottie e, de roldão, o idealismo platônico, a cosmologia ptolomaica e a distinção judaico-cristã entre paraíso e inferno. O que nos remete menos à maçã enquanto símbolo da teoria newtoniana da gravidade e mais à síntese que esta teoria opera: a de igualar céu e terra.

A genialidade de Newton foi vigorosa na ousadia de propor que a queda de um objeto qualquer nas proximidades do solo, como um fruto que cai de uma árvore ou um copo de uma mesa, tinha como causa uma força da mesma natureza das forças que regem os movimentos dos planetas ao redor do Sol e que mantêm o cosmo coeso, fazendo indistintos, em última análise, céu e terra. Como indicam as pesquisas de Betty Dobbs [10], Newton tirou inspiração para a concepção da força da gravidade universal da máxima da Tábua de Esmeralda, atribuída a Hermes Trismegisto: "O que está em cima é como o que está embaixo". Perscrutando o discurso de Deus na natureza, Newton atribui à

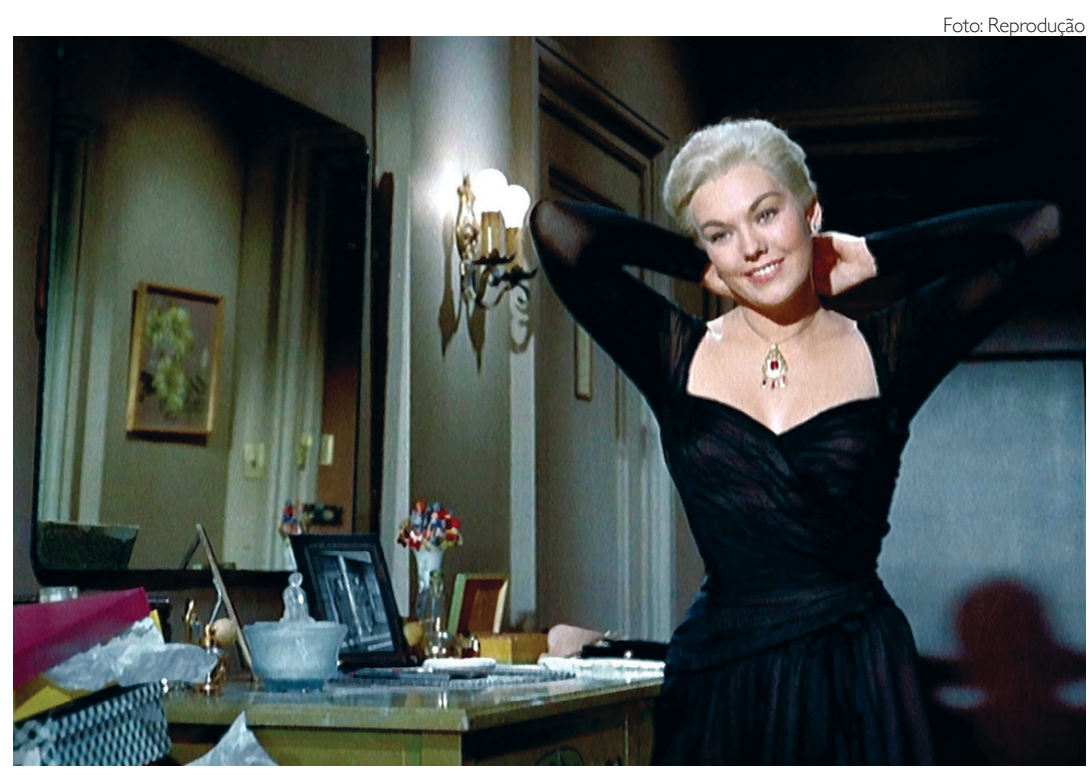

Figura 2. Cena em que Judy distraidamente coloca o colar de Carlotta queda de um fruto as mesmas causas que atribuiu ao movimento dos corpos celestes e desenvolveu matematicamente uma teoria compatível com as leis de Kepler, com a força de atração variando na razão inversa do quadrado das distâncias. A parábola descrita pelos corpos lançados 


\section{Artigos $\odot$ Ensaios}

obliquamente próximos à superfície terrestre, a elipse da trajetória dos planetas ao redor do Sol e a hipérbole do movimento de cometas pertencem à mesma família das secções de um cone.

A gravidade seria, segundo Newton, exercida por Deus, que está por toda parte, reformando o universo e agindo constantemente sobre ele como agente da força gravitacional. Ele não formulou hipóteses sobre as causas da gravidade, mas é bem conhecida sua afirmação no Escólio Geral dos Principia:

"Tão elegante combinação de Sol, planetas e cometas, só pode ter origem na inteligência e no poder de um ente inteligente e poderoso. [...] E para que os sistemas das [estrelas] fixas não caiam uns sobre os outros pela gravidade, Ele os colocou a imensas distâncias uns dos outros." [11]

Em Ferreiros e alquimistas, a partir de estudos sobre técnicas primitivas, Mircea Eliade [12] mostra como tecnicidade e sacralidade eram indiscerníveis nos limites extremos do conhecimento. Newton, cuja obra científica tira vigor e impulso da metafísica, via na expressão matemática de uma teoria científica a tradução do discurso de Deus oculto na natureza. Ao igualar céu e terra com a mesma força de natureza gravitacional e ao atribuir a um agente divino a ação dessa força, Newton atualiza o amálgama primitivo entre o técnico e o sagrado.

A queda é uma iguaria filosófica no filme de Hitchcock porque nela reverberam o pecado original, a obra de Platão. Mas também porque insinua o Axis Mundi, a correspondência entre os reinos superiores e inferiores, a subversão do platonismo contida na máxima da Tábua de Esmeralda, tão cara a Isaac Newton como inspiradora para a síntese que ele operou.

A síntese é também insinuada na terceira estrofe da poesia da canção "Pecado original": Todo beijo, todo medo / Todo corpo em movimento / Está cheio de inferno e céu / Todo santo, todo canto / Todo pranto, todo manto / Está cheio de inferno e céu / O que fazer com o que Deus nos deu? / O que foi que nos aconteceu?

Márcio Barreto é docente da Faculdade de Ciências Aplicadas da Universidade Estadual de Campinas (FCA-Unicamp).

\section{NOTAS E REFERÊNCIAS}

1. Jung, C. G. O homem e seus simbolos. 1a Edição. Rio de Janeiro: Harper Collins Brasil, 2016.

2. Há apenas um relato no manuscrito da biografia de Newton, publicada em 1752 e da autoria de William Stukeley, sobre uma explicação que Newton teria dado sobre a gravidade na qual ele usa a queda de uma maçã como exemplo.

3. Whitehead, A. N. "Le symbolisme as signification et as portée". In: La fonction de la raison et autres essais. Paris: Payot, 1969. p.79. Minha tradução.

4. Einstein, A. In: Pais, A. "Sutil é o senhor: a ciência e a vida de Albert Einstein". Rio de Janeiro, Editora Nova Fronteira, 1993, p.225.

5. Zizek, S. Tout ce que vous avez toujours voulu savoir sur Lacan sans jamais oser le demander a Hitchcock. Paris: Navarian, 1988.

6. Santos, L. G. Politizar as novas tecnologias. 1a Edição. São Paulo: Editora 34, 2003. p. 202.

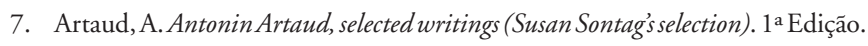
Berkeley: University of California Press, 1988.

8. Deleuze, G. A imagem-tempo. São Paulo:Brasiliense, 2005. p. 203.

9. Barbaras, R. Investigaçōes fenomenológicas: em direção a uma fenomenologia da vida. $1^{\text {a }}$ Edição. Curitiba: Editora da UFPR, 2011. p.43.

10. Dobbs, B J. T. The Foundations of Newton's Alchemy. $1^{\text {a }}$ Edição. Nova Iorque, Cambridge University Press, 1984.

11. Newtin, I. Principios matemáticos de la filosofía natural. $1^{\text {a }}$ Edição. Madrid: Alianza Editorial, 1987, p.782.

12. Eliade, M. Ferreiros e alquimistas. 1ª Edição. Lisboa: Relógio D'água, 1987. 